\title{
PENSAMENTO CRÍTICO NA CIÊNCIA: Perspectiva dos Livros Didáticos Brasileiros
}

\author{
Kélli Renata Corrêa de Mattos ${ }^{1}$ \\ Roque Ismael da Costa Güllich ${ }^{2}$ \\ Luiz Caldeira Brant de Tolentino Neto ${ }^{3}$
}

\begin{abstract}
RESUMO
A educação em Ciências ocupa papel central na formação dos sujeitos contemporâneos. Com uma formação que não priorize somente conceitos científicos, mas também conhecimentos contextualizados, o aluno é auxiliado na compreensão e atuação social. Nesse contexto, considera-se a promoção do Pensamento Crítico (PC) como uma abordagem em potencial. Pensando nisso, realizou-se uma análise documental em oito Livros Didáticos (LD) do 70 ano do Ensino Fundamental, identificando a natureza das atividades propostas bem como o potencial das mesmas para o desenvolvimento das capacidades do PC. Percebe-se, com a análise, a diversidade de atividades presentes nos LDs de Ciências, posto que as mais recorrentes foram classificadas na categoria Exploratórias, as quais conferem a oportunidade de o sujeito se envolver no processo a depender do encaminhamento pedagógico, seguido das atividades classificadas como Reflexivas/Críticas, as quais desempenham um papel crucial na formação do sujeito, instigando-o a pensar, refletir e criticar. Verifica-se, ainda, a presença de atividades mais tradicionais classificadas na categoria Informativa, pois apenas têm o intuito de apresentar uma informação adicional ao conteúdo. Considera-se, contudo, os resultados satisfatórios, pois expressam que os LDs de Ciências não possuem predominantemente atividades simplistas e tradicionais, mas que têm avançado em relação ao caráter das atividades propostas.
\end{abstract}

Palavras-chave: Ensino de Ciências. Currículo. Estratégias de ensino.

\section{CRITICAL THINKING IN SCIENCE: PERSPECTIVE FROM BRAZILIAN TEXTBOOKS}

\begin{abstract}
Science education plays a central role in the formation of contemporary subjects. With an education that not only prioritizes scientific concepts, but also contextualized knowledge, the student is assisted in understanding and social action. In this context, the promotion of Critical Thinking (CT) is considered a potential approach. Thinking about it, a documentary analysis was made in 8 textbooks of the 7th grade of Elementary School, identifying the nature of the proposed activities, as well as their potential for the development of the capacities of CT. With the analysis, one can perceive the diversity of activities present in the textbooks of Sciences, being that the most recurrent ones were classified in the Exploratory category, which confer the opportunity of the subject to get involved in the process, depending on the pedagogical forwarding. Followed by the activities classified as Reflective/Critical, which play a crucial role in the formation of the subject, encouraging him/her to think, reflect and criticize. There is also the presence of more traditional activities classified in the Informative category, since they only have the purpose of presenting additional information to the content. However, the results are considered satisfactory, since they express that the textbooks of Sciences do not have predominantly simplistic and traditional activities, but have advanced in relation to the character of the proposed activities.
\end{abstract}

Keywords: Science teaching; Curriculum; Teaching strategies.

Recebido em: $17 / 5 / 2019$

Aceito em: $10 / 6 / 2020$

\footnotetext{
1 Autora correspondente. Universidade Federal de Santa Maria (UFSM). Av. Roraima no 1000 - Cidade Universitária, Bairro Camobi. CEP 97105900. Santa Maria/RS, Brasil. http://lattes.cnpq.br/6384163881176958. https://orcid.org/0000-0002-4671-3247. kellic.mattos@gmail.com

2 Universidade Federal da Fronteira Sul, Campus de Cerro Largo. Cerro Largo/RS, Brasil. http://lattes.cnpq.br/9570948289140345. https:// orcid.org/0000-0002-8597-4909

3 Universidade Federal de Santa Maria (UFSM). Santa Maria/RS, Brasil. http://lattes.cnpq.br/5626168979329885. https://orcid.org/00000001-6170-1722.
} 
O ensino de Ciências tornou-se um desafio para a educação. Com a abundância de informações disponíveis, decorrentes do avanço da Ciência e da Tecnologia, a informação aumenta e, por vezes, pode colocar em xeque o conhecimento já construído. A informação, todavia, não é conhecimento, tampouco conhecimento científico, o qual requer um alto grau de rigor e fidedignidade (FREIRE, 2007). Entende-se que não se faz necessário apenas o desenvolvimento do conhecimento científico, mas, sim, a promoção do desenvolvimento de um Pensamento Crítico (PC) como forma de melhor pensar a produção e o uso dos conhecimentos científicos. A necessidade de fomentar o desenvolvimento do PC decorre, sobretudo, do reconhecimento de que ele é essencial para viver em sociedade, pois as capacidades do PC tornam o sujeito esclarecido cientificamente, reflexivo, autônomo e apto para solucionar problemas e tomar decisões no meio em que vive (TENREIRO-VIEIRA, 2000).

Tendo em vista as implicações da atual era digital, que viabiliza o acesso a diversas informações de diferentes áreas do saber, o sujeito necessita utilizar o seu próprio senso crítico como filtro dessas informações. Diante desse leque de informações e também conhecimentos, os sujeitos podem ter interesse por diversas áreas, e o PC pode ser uma possibilidade de compreensão de mundo, possibilitando uma visão peculiar a respeito de distintos temas (SILVA, 2016). Entende-se o PC como uma perspectiva de ensino que tem como base a formação de cidadãos. Assim, o desenvolvimento do PC pode ocorrer por meio de estratégias que priorizam a constituição de um sujeito ativo, reflexivo, autônomo, responsivo e, sobretudo, crítico. Quando se fala nestes termos é importante destacar que os tratamos à luz da perspectiva de Ennis (1985, p. 46) sobre o PC, que o compreende como sendo "uma forma de pensamento racional, reflexivo, focado no decidir aquilo em que acreditar ou fazer", concordando com Tenreiro-Vieira (2000, p. 20), quando afirma que "esta via racional permite-lhe analisar, decidir aquilo que é verdadeiro, dominar e controlar o seu próprio conhecimento e adquirir novo conhecimento".

Para que o PC, todavia, seja inserido e promovido em sala de aula, toda a comunidade escolar precisa estar envolvida no processo educacional, desenvolvendo trabalho colaborativo, harmônico e responsivo para com a formação dos sujeitos. É importante que os professores reconheçam a potencialidade que há nas estratégias de ensino do PC nas aulas de Ciências, explorando mais a experimentação, a constituição de debates, práticas pedagógicas, fóruns, entre outras. Por intermédio de atividades que envolvam resolução de problemas, os alunos e professores compõem um momento de discussões, questionamentos, reflexões e tomadas de decisão, ações estas indispensáveis para a constituição de sujeitos autônomos e críticos. Uma formação inicial e continuada de qualidade, que valorize a promoção do PC e seus desdobramentos e aplicações no ensino de Ciências, representa um subsídio para o desencadeamento de práticas docentes direcionadas a uma aprendizagem por meio da reflexão crítica (DEWEY, 1989), a qual prioriza o contexto social e escolar do aluno, instigando o mesmo a reconhecer o seu potencial como ser humano racional, capaz de (re)construir seus próprios conhecimentos (TENREIRO-VIEIRA; VIEIRA 2001; TENREIRO-VIEIRA, 2000; DEWEY, 1989).

Por outro lado, mesmo que o professor tenha tido uma formação nas perspectivas do PC, o mesmo não é o único responsável por melhorias no cenário educacional, sendo tão somente uma das peças-chave para a mudança, estando em jogo, ainda, as diretri- 
zes curriculares, o currículo, os Livros Didáticos (LDs), as práticas, a relação com a comunidade escolar, o contexto e, em especial, as próprias Políticas Públicas Educacionais (PPEs), pensando sob um aspecto macro em relação à responsabilidade com a educação. Todos esses fatores são basilares e inerentes à conjuntura do processo educacional, e, entre eles, destaca-se o LD, garantido às escolas por meio do Programa Nacional do Livro Didático (PNLD), posto que o mesmo se tornou, também, um grande influenciador do processo de ensino e aprendizagem. Percebe-se que o ensino das áreas científicas é muito atrelado ao uso quase exclusivo do LD, uma vez que este uso indiscriminado chega a aprisionar o fazer docente, expropriando o trabalho do professor (GERALDI, 1994; FRACALANZA, 2006a).

Os LDs de Ciências têm sido alvo de críticas desde a década de 70 do século 20, portanto a literatura permite afirmar que eles possuem equívocos e discrepâncias não somente em relação à disposição dos conteúdos, mas, também, quanto à escolha das atividades propostas, podendo ser eventualmente causadores de equívocos no processo de ensino e aprendizagem, tendo em vista o fato de que, por vezes, a didática do professor é baseada na maquinaria pedagógica apresentada pelo livro (GERALDI, 1994; SELLES; FERREIRA, 2004; FRACALANZA, 2006a; GÜLLICH, 2013). Entende-se a centralidade do LD no ensino, pois o mesmo é uma das possibilidades mais palpáveis oferecidas aos professores, os quais normalmente enfrentam sérios problemas de infraestrutura para o desempenho de suas práticas (AMARAL, 2006; OSSAK; BELLINI, 2009). A mercê, porém, do que o LD traz, sem a mediação do professor e sem metodologias de ensino instigantes, a aula pode tornar-se desmotivadora, reproducionista, monóloga e passiva, o que revela a importância da análise dos LDs para que não ocorra grande perda do fundamento educacional nessa possível relação de adoção do LD pelo professor ou vice-versa (GÜLLICH; WALCZAK; MATTOS, 2016).

\section{PENSAMENTO CRÍTICO NO ENSINO DE CIÊNCIAS}

A promoção das capacidades do PC pode ser resumida de acordo com Tenreiro-Vieira e Vieira (2013b, p. 183) em: "analisar e avaliar informação, evidência e argumentos; formular e testar hipóteses e conjecturas; tirar e avaliar conclusões; fazer e avaliar generalizações; fazer e avaliar juízos de valor; argumentar; comunicar; avaliar", entre outras. Compreende-se a importância do desenvolvimento dessas capacidades, em especial para o ensino de Ciências, tendo em vista que elas tendem a "estimular as pessoas a usar informação e formas de pensar, incluindo o pensar de forma crítica, para a tomada de decisão esclarecida e racional, para a resolução de problemas e para a participação ativa e responsável numa sociedade democrática" (TENREIRO-VIEIRA; VIEIRA, 2014, p. 8). Isso infere, ainda, que as capacidades de PC tendem a migrar do ensino para a vida social do sujeito, de modo que, uma vez desenvolvidas, passam a influenciar diretamente as ações e relações do sujeito em seu cotidiano, tornando-se, portanto, essenciais não somente em contexto educacional, mas também social (WALCZAK; MATTOS; GÜLLICH, 2017).

Tendo o PC como uma proposta de ensino, cabe discutir questões como a formação de professores qualificados nessa perspectiva, o uso de estratégias/metodologias de ensino que fomentem o desenvolvimento das capacidades do PC, além dos LDs que constituem a nossa análise central, voltada para a verificação da presença de atividades 
promotoras ou não do PC. Sendo assim, inicialmente é necessário que haja coerência entre a ideia de currículo oficial orientado pela Lei de Diretrizes e Bases de 1996, que aponta para a formação de uma pessoa crítica, e o currículo em ação nas escolas, que, de fato forma ou não um sujeito crítico. $O$ ensino em geral, porém, não apresenta medidas que demonstrem a intenção da inserção do PC, de modo que, eventualmente, alguns professores podem não ter acesso a uma formação de qualidade e, assim, acabam por não instigar a autonomia dos alunos, para que consigam pôr em prática o seu senso crítico e reflexivo, tanto para a resolução de problemas quanto para tomadas de decisão (TENREIRO-VIEIRA, 2004; BRASIL, 2005).

A ausência de atividades de caráter crítico nos LDs e nas práticas, todavia, está intrinsecamente relacionada à formação dos professores como já citado, pois, como afirma Tenreiro-Vieira (2000, p. 16): “o professor só poderá apelar para a manifestação, utilização e desenvolvimento das capacidades do Pensamento Crítico dos alunos, se ele próprio manifestar e utilizar estas capacidades". Não é possível cobrar de um professor, portanto, uma docência intencionada para o PC se ele não teve formação inicial e continuada adequada. Nessa perspectiva, aponta-se para a formação inicial e continuada de professores como uma medida fundamental para que ocorram as mudanças necessárias no cenário educacional. Em relação à formação de professores para o PC, Tenreiro-Vieira (2004, p. 247) afirma que "diferentes programas de formação em pensamento crítico influenciam diferentemente as práticas docentes ao pensamento crítico". Isto demonstra que a formação tem resultados positivos, pois os professores envolvidos no processo apresentam melhor domínio das capacidades do PC, sendo capazes, assim, de construir atividades com este caráter, além de distinguir o material didático com maior potencial para a promoção do PC.

Quanto às metodologias de ensino, Tenreiro-Vieira e Vieira (2013a) ressaltam que existem poucos estudos focados no estabelecimento de estratégias promotoras do PC no ensino de Ciências. Sabe-se, porém, que algumas atividades possuem potencial de instigar mais o aluno do que outras, como é o caso de debates, resolução de problemas, questionamentos e atividades experimentais, que se caracterizam como atividades propulsoras da ação de refletir, criticar, pesquisar e investigar (MATTOS et al., 2017).

Em relação aos Livros Didático de Ciências (LDCs), ressalta-se, novamente, a problemática base, que é o fato de que ainda muitos professores fazem uso excessivo do mesmo. Esta ação pode colocar em jogo a aprendizagem dos alunos, pois nem todos os LDCs são materiais absolutamente confiáveis, isto é, muitos eventualmente podem apresentar falácias e/ou defasagens em relação ao conteúdo, além da ausência de atividades que proporcionem a reflexão e a criticidade dos alunos, as quais, por sua vez, contribuem para que eles atuem como protagonistas dos seus próprios conhecimentos (GERALDI, 1994; FRACALANZA; MEGID NETO, 2003; FRACALANZA, 2006b).

Com isso, aposta-se em análises que mais bem contemplem alguns temas, como: metodologias críticas e reflexivas, formação de professores de qualidade, uso e reconhecimento do papel do LD e avaliação, entre outras temáticas relevantes ao ensino e aprendizagem de Ciências (FRACALANZA, 2006a; GÜLLICH; SILVA; ANTUNES, 2011; MARIM; SOUZA, 2015; ROSA; MOHR, 2016). Com base nas discussões e reflexões articuladas até o momento, o LD é visto como um dos fatores determinantes para a promoção 
das capacidades do PC no ensino de ciências, especialmente em contexto brasileiro. Por isso, esta pesquisa tem como objetivo analisar o LD de Ciências do 70 ano do Ensino Fundamental, verificando a presença, em seu enredo, de atividades que favoreçam a promoção do PC no processo de ensino e aprendizagem em Ciências da Natureza.

\section{PERCURSO METODOLÓGICO}

Esta pesquisa de educação em Ciências tem abordagem qualitativa e parte da análise documental de Livros Didáticos de Ciências do Ensino Fundamental (LDCEF) do 70 ano do Ensino Fundamental, sendo desenvolvida em três etapas: pré-análise, exploração do material e tratamento e interpretação dos resultados (LÜDKE; ANDRÉ, 2001), com o intuito de verificar o caráter pedagógico das atividades nos LDs bem como se possuem potencial para a promoção do PC em Ciências. Para a realização da análise utilizou-se oito LDCEFs das escolas da Região das Missões no Rio Grande do Sul (RS), sendo os mesmos avaliados pelo Programa Nacional do Livro Didático (PNLD) nos ciclos de 2003, 2006, 2009, 2012 e 2015. Como cada ciclo tem duração três anos, os LDCs analisados têm edições entre os anos de 2000 a 2017.

Assim, realizou-se a coleta dos dados sistematizando-se todas as atividades propostas nos LDCEFs em um quadro inicial para facilitar a identificação das atividades encontradas. Além disso, optou-se por denominar as atividades de descritores. Com base nos descritores, ou seja, nas atividades encontradas, passou-se para a construção das categorias de análise de estudo tendo como subsídio Lüdke e André (2001, p. 50), os quais afirmam que "a construção de categorias não é tarefa fácil. Elas são construídas num primeiro momento do arcabouço teórico [...], vão se modificando num processo dinâmico [...], em que se originam novas concepções e consequentemente, novos focos de interesse". Pensando nesse processo dinâmico de (re)conhecimento dos dados produzidos, do alicerce teórico e das concepções dos autores para a construção das categorias, adota-se como base para a identificação e classificação das atividades as perspectivas de PC em Ciências, a qual requer um pensamento racional e reflexivo, com atividades que priorizem a capacidade de análise e decisão, além de domínio e controle do próprio conhecimento e de um novo (ENNIS, 1985; TENREIRO-VIEIRA; VIEIRA, 2001; TENREIRO-VIEIRA, 2000).

Ainda, concordando com a ideia de Guba e Lincoln (1986 apud LÜDKE; ANDRÉ, 2001, p. 51), que considera que "as categorias devem antes de tudo refletir os propósitos da pesquisa", construiu-se as categorias com base nos dados coletados, projetando o agrupamento das atividades em razão da natureza pedagógica das mesmas. Assim, elencou-se as categorias emergentes da análise, a saber: 1 - Informativas; 2 - Exploratórias e 3 - Reflexivas/Críticas, as quais possuem, ainda, as suas respectivas subcategorias e descritores. Neste estudo, os LDs serão denominados LDC 1, LDC 2, LDC 3 e, respectivamente, até LDC 8, para possível identificação da ocorrência das categorias, subcategorias e descritores nos mesmos.

\section{RESULTADOS E DISCUSSÃO}

Tendo em vista a análise realizada em torno do conteúdo das atividades propostas nos oito LDCs, obteve-se, com base nos resultados, a formação de três principais categorias empíricas e suas respectivas subcategorias, elaboradas com base nos descritores (atividades) 
encontrados. Assim, classifica-se as subcategorias em categorias maiores, de acordo com o potencial de promover a reflexão e criticidade do aluno. Dessa forma, foram elaboradas as três categorias mais abrangentes, embasadas na proposta das atividades encontradas, sendo elas: 1) Informativas, em que foram agrupados os descritores que tinham o objetivo de somente informar algo; 2) Exploratórias, em que foram agrupados os descritores que apresentavam condições de expansão da atividade, além do que foi proposto no enunciado; e 3) Reflexivas/Críticas, em que foram agrupados os descritores com capacidades de instigar o sujeito a pesquisar, investigar, refletir, questionar e criticar, facilitando o desenvolvimento da sua autonomia intelectual e, possivelmente, a promoção do PC em ciências

Os descritores/atividades presentes nos LDCs possibilitaram a sistematização das seguintes categorias e subcategorias: 1) Categorias Informativas, com subcategorias: 1a. Leitura; 1b. Nota explicativa e 1c. Informações complementares; 2) Categorias Exploratórias, com as subcategorias 2a. Estudo do texto; 2b. Exercícios; 2c. Desafios; 2d. Referências na Web; 2e. Atividades sobre o tema; 2f. Organização de ideias; $2 \mathrm{~g}$. Problematização; 2h. Interpretação de texto e 2i. Experimento; e 3) Categorias Reflexivas/Críticas, com as subcategorias 3a. Trabalho em grupo; 3b. Pesquisa; 3c. Prática pedagógica; 3d. Abordagem CTS/CTSA e 3e. Oficinas. Destaca-se, novamente, que as subcategorias se constituíram tendo como ponto de partida a natureza das atividades pedagógicas presentes nos LDCEFs (ver Quadro 1).

Quadro 1 - Sistematização das categorias e subcategorias emergentes dos descritores dos LDCEF

\begin{tabular}{|c|c|c|}
\hline Categorias & Subcategorias & Descritores \\
\hline \multirow{3}{*}{ 1. Informativas } & 1a. Leitura & $\begin{array}{l}\text { Você vai gostar de ler; Leitura complementar; Não deixe } \\
\text { de ler. }\end{array}$ \\
\hline & 1b. Nota explicativa & Saiba mais. \\
\hline & $\begin{array}{l}\text { 1c. Informações } \\
\text { complementares }\end{array}$ & $\begin{array}{l}\text { Certifique-se de ter lido direito; Glossário A-Z; Saiba de } \\
\text { onde vêm as palavras; Isso entra no nosso vocabulário. }\end{array}$ \\
\hline \multirow{9}{*}{ 2. Exploratórias } & 2a. Estudo do texto & $\begin{array}{l}\text { Trabalhando a leitura; Cientista detetive; De olho no } \\
\text { texto; Explore linguagens; Explore; Nós; Fórum. }\end{array}$ \\
\hline & 2b. Exercícios & $\begin{array}{l}\text { Integrando conhecimento; Pense e responda; Pense um } \\
\text { pouco mais; Use o que aprendeu; Atividades; Faça seu } \\
\text { próprio resumo; Discuta/trabalhe esta ideia; Desafio; } \\
\text { Reflita sobre suas atitudes; Pense nesse problema; Para } \\
\text { fazer no caderno; Estabeleça conexões. }\end{array}$ \\
\hline & 2c. Desafios & Desafio do presente e passado. \\
\hline & 2d. Referência na web & Entrando na rede; Conteúdo digital; Use a internet. \\
\hline & 2e. Atividade sobre o tema & De olho no tema. \\
\hline & 2f. Organização de ideias & Mapas conceituais. \\
\hline & 2.g Problematização & $\begin{array}{l}\text { Motivação; Ponto de partida; Ponto de chegada; A } \\
\text { questão é; Começando a unidade; Porque estudar esta } \\
\text { unidade; Seu aprendizado não termina aqui. }\end{array}$ \\
\hline & 2h. Interpretação de texto & $\begin{array}{l}\text { Para saber mais; Para ler o texto científico; Compreender } \\
\text { o texto; Para ir mais longe; Rede do tempo; Em destaque; } \\
\text { Pensar Ciência; Coletivo Ciências; Multiletramentos. }\end{array}$ \\
\hline & 2.i Experimento & $\begin{array}{l}\text { No laboratório; Experimentação-faça você mesmo; Mãos } \\
\text { à obra: atividade prática ou experimental; Aprendendo } \\
\text { com a prática. }\end{array}$ \\
\hline
\end{tabular}




\begin{tabular}{|l|l|l|}
\hline \multirow{3}{*}{$\begin{array}{l}\text { 3. Reflexivas/ } \\
\text { Críticas }\end{array}$} & 3a. Trabalho em grupo & $\begin{array}{l}\text { Trabalho em equipe; Em grupo; Atividade em grupo; Para } \\
\text { discussão em grupo. }\end{array}$ \\
\cline { 2 - 3 } & 3b. Prática pedagógica & Vamos fazer; Descubra; Experimento da hora. \\
\cline { 2 - 3 } & $\begin{array}{l}\text { 3ensando e pesquisando; Tema para pesquisa; Mexa-se; } \\
\text { Isso vai para o nosso mural. }\end{array}$ \\
\cline { 2 - 3 } & 3d. Abordagem CTS/CTSA & $\begin{array}{l}\text { Ciência...; Por uma nova atitude; Ciência Tecnologia, } \\
\text { Sociedade e Ambiente em pauta; Boxes CTS. }\end{array}$ \\
\cline { 2 - 3 } & 3e. Oficinas de Ciências & Oficinas, Projeto, Pensar, fazer compartilhar. \\
\hline
\end{tabular}

Fonte: Os autores, 2018. Nota: construída com base na pesquisa empírica em LDCEF.

Os resultados desta pesquisa apontam para um grande número e diversidade de atividades com diferentes nomenclaturas, mas com proposta pedagógica igual ou semelhante. Um exemplo disto está ligado à categoria 2) Exploratórias, na subcategoria 2b. Exercícios, em que se encontram descritores denominados, por exemplo, de "Faça seu próprio resumo; Desafio; Explore", enquanto a atividade proposta em ambos refere-se apenas à resolução de questões. Embora, portanto, haja a ocorrência de múltiplas terminologias que fazem menção a uma mesma atividade nos LDCEFs, agrupa-se todas as atividades do mesmo caráter em subcategorias que refletem, de fato, a natureza pedagógica desta e não apenas o que o descritor - título da atividade - descreve/aponta. Além da categorização, realiza-se o levantamento da frequência dos descritores/atividades nos LDCEFs, como pode-se observar no Quadro 2.

Quadro 2 - Ocorrência dos descritores/atividades pedagógicas nos LDCEF

\begin{tabular}{|c|c|c|c|}
\hline Subcategoria & Descritores & Livros Didáticos & Frequência (f) \\
\hline \multirow{3}{*}{ 1a. Leitura } & Não deixe de ler & LDC6 & 1 \\
\hline & Você vai gostar de ler & LDC2 & 5 \\
\hline & Leitura complementar & LDC5 & 50 \\
\hline \multirow{3}{*}{ 1b. Nota explicativa } & \multirow{3}{*}{$\begin{array}{l}\text { Saiba mais } \\
\text { Saiba mais } \\
\text { Saiba mais }\end{array}$} & LDC7 & 23 \\
\hline & & LDC8 & 25 \\
\hline & & LDC1 & 31 \\
\hline \multirow{6}{*}{$\begin{array}{l}\text { 1c. Informações } \\
\text { complementares }\end{array}$} & \multirow[t]{3}{*}{ Glossário A-Z } & LDC8 & 12 \\
\hline & & LDC7 & 29 \\
\hline & & LDC5 & 101 \\
\hline & Certifique-se de ter lido direito & LDC6 & 10 \\
\hline & Saiba de onde vêm as palavras & LDC6 & 10 \\
\hline & Isso entra no nosso vocabulário & LDC6 & 38 \\
\hline \multirow{9}{*}{ 2a. Estudo do texto } & Cientista detetive & LDC1 & 4 \\
\hline & Nós & LDC4 & 8 \\
\hline & Fórum & LDC4 & 9 \\
\hline & De olho no texto & LDC5 & 9 \\
\hline & Explore linguagens & LDC6 & 18 \\
\hline & Trabalhando a leitura & LDC1 & 20 \\
\hline & \multirow[t]{3}{*}{ Explore } & LDC7 & 8 \\
\hline & & LDC8 & 16 \\
\hline & & LDC4 & 21 \\
\hline
\end{tabular}




\section{Revista \\ \&Educaçã̃o}

Pensamento Crítico na Ciência: Perspectiva dos Livros Didáticos Brasileiros

2b. Exercícios

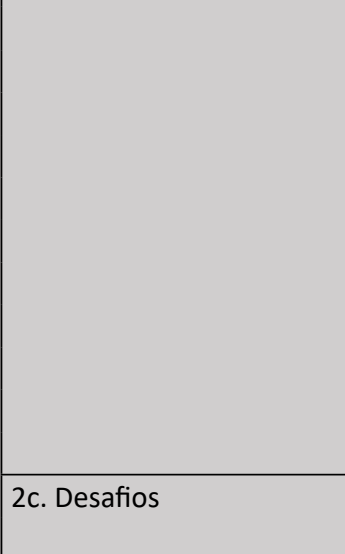

2d. Referências da Web

2h. Interpretação de texto

2.i Experimento

2e. Atividade sobre o tema

2f. Organização de ideias

2.g Problematização

$$
\text { o }
$$

\begin{tabular}{|l|l} 
Para fazer no caderno & \\
\hline Reflita sobre suas atitudes & \\
\hline Desafio &
\end{tabular}

Estabeleça conexões

Pense nesse problema

Use o que aprendeu

Faça seu próprio resumo

Pense e responda

Pense um pouco mais

Integrando conhecimento

\begin{tabular}{l}
\hline Pe \\
\hline Co \\
\hline Co \\
\hline
\end{tabular}

Porque

Discuta/trabalhe esta ideia

Desafio do presente e passado

Entrando na rede

Use a internet

De olho no tema

Mapas conceituais

Começando a unidade

Porque estudar esta unidade

Ponto de partida/chegada

Seu aprendizado não termina aqui

Motivação

A questão é

Para saber mais

Multiletramentos

Coletivo Ciências

Rede do tempo

Pensar Ciência

Para ler o texto científico

Compreender o texto

Para ir mais longe

Em destaque

Mãos à obra: atividade prática ou experimental

No laboratório

Experimentação faça você mesmo

Aprendendo com a prática

Contexto \& Educação

Editora Unijuí •ISSN 2179-1309 • Ano 36 • no 114 • Maio/Ago. 2021

\begin{tabular}{|c|c|}
\hline LDC6 & 2 \\
\hline LDC6 & 8 \\
\hline LDC4 & 9 \\
\hline LDC6 & 9 \\
\hline LDC1 & 15 \\
\hline LDC6 & 16 \\
\hline LDC1 & 20 \\
\hline LDC4 & 29 \\
\hline LDC5 & 29 \\
\hline LDC3 & 18 \\
\hline LDC2 & 23 \\
\hline LDC8 & 16 \\
\hline LDC4 & 18 \\
\hline LDC5 & 30 \\
\hline LDC7 & 31 \\
\hline LDC2 & 76 \\
\hline LDC3 & 84 \\
\hline LDC2 & 14 \\
\hline LDC3 & 19 \\
\hline LDC8 & 4 \\
\hline LDC7 & 10 \\
\hline LDC8 & 7 \\
\hline LDC6 & 10 \\
\hline LDC6 & 18 \\
\hline LDC8 & 40 \\
\hline LDC7 & 46 \\
\hline LDC6 & 19 \\
\hline LDC8 & 7 \\
\hline LDC7 & 8 \\
\hline LDC8 & 7 \\
\hline LDC7 & 8 \\
\hline LDC5 & 8 \\
\hline LDC6 & 19 \\
\hline LDC6 & 27 \\
\hline LDC5 & 29 \\
\hline LDC5 & 6 \\
\hline LDC4 & 6 \\
\hline LDC7 & 7 \\
\hline LDC4 & 8 \\
\hline LDC7 & 8 \\
\hline LDC4 & 9 \\
\hline LDC7 & 8 \\
\hline LDC8 & 9 \\
\hline LDC3 & 19 \\
\hline LDC2 & 22 \\
\hline LDC6 & 22 \\
\hline LDC2 & 5 \\
\hline LDC3 & 12 \\
\hline LDC7 & 8 \\
\hline LDC1 & 10 \\
\hline LDC5 & 10 \\
\hline
\end{tabular}




\begin{tabular}{|c|c|c|c|}
\hline \multirow{5}{*}{ 3a. Trabalho em grupo } & Trabalho em equipe & LDC6 & 7 \\
\hline & Para discussão em grupo & LDC6 & 10 \\
\hline & Atividade em grupo & LDC5 & 15 \\
\hline & \multirow[t]{2}{*}{ Em grupo } & LDC3 & 30 \\
\hline & & LDC2 & 46 \\
\hline \multirow{3}{*}{ 3b. Prática pedagógica } & Descubra & LDC8 & 1 \\
\hline & Vamos fazer & LDC7 & 2 \\
\hline & Experimento da hora & LDC4 & 7 \\
\hline \multirow{4}{*}{ 3c. Pesquisa } & Isso vai para o nosso mural & LDC6 & 4 \\
\hline & Tema para pesquisa & LDC6 & 10 \\
\hline & Mexa-se & LDC5 & 15 \\
\hline & Pensando e pesquisando & LDC1 & 20 \\
\hline \multirow{6}{*}{ 3d. Abordagem CTSA } & \multirow[t]{2}{*}{ Por uma nova atitude } & LDC7 & 8 \\
\hline & & LDC8 & 8 \\
\hline & Ciência & LDC4 & 12 \\
\hline & \multirow[t]{2}{*}{ CTSA em pauta } & LDC8 & 5 \\
\hline & & LDC7 & 15 \\
\hline & Boxes CTS & LDC5 & 33 \\
\hline \multirow{5}{*}{ 3e. Oficinas de Ciências } & \multirow[t]{2}{*}{ Projeto } & LDC7 & 1 \\
\hline & & LDC6 & 10 \\
\hline & \multirow[t]{2}{*}{ Oficinas } & LDC7 & 7 \\
\hline & & LDC8 & 8 \\
\hline & Pensar, fazer compartilhar & LDC8 & 8 \\
\hline
\end{tabular}

Fonte: Os autores, 2018. Nota: Os descritores: Leitura complementar (50), Oficinas (8) e Projetos (10) foram encontrados somente no final dos LDCs.

Com base no Quadro 2 observa-se o grande número de descritores encontrados nos LDCEFs, a frequência dos mesmos e como alguns descritores repetem-se em mais de um LDCEF. Há uma grande diversidade de atividades, pois em alguns livros analisados todas as páginas apresentam uma ou mais atividades, posto que a grande maioria destas são de fixação e/ou memorização e não atividades de resolução de problemas, reflexão e tomadas de decisão, que têm um maior potencial em relação à significação conceitual no processo de ensino e aprendizagem em Ciências (NúÑEZ et al., 2003).

Na categoria 1) Informativas há três subcategorias: 1a. Leitura; 1b. Nota explicativa e 1c. Informações complementares. Na 1a. Leitura foram encontrados os descritores: Você vai gostar de ler (5 em LDC 2); Leitura complementar (50 em LDC 5) e Não deixe de ler (1 em LDC 6), porém todos são textos apenas para leitura, por isso classificados como atividades exclusivamente informativas. Na subcategoria 1b. Nota explicativa, percebe-se um descritor muito frequente em três LDs, os quais apareciam com a mesma denominação: Saiba mais (31 em LDC 1; 23 em LDC 7; 25 em LDC 8), e todos consistiam em um quadro com informações adicionais sobre o conteúdo tratado no capítulo. Na subcategoria 1c. Informações complementares foram encontrados os seguintes descritores: Certifique-se de ter lido direito (10 em LDC 6); Glossário (101 em LDC 5; 29 em LDC 7; 12 em LDC 8) e Saiba de onde vêm as palavras (10 em LDC 6), todos com o intuito de trazer informações complementares.

O Glossário é um exemplo de descritor encontrado em mais de um LDC, sendo, portanto, uma atividade bem recorrente; o texto complementar, todavia, é apenas informativo; não tem perfil instigador e reflexivo, configurando-se como uma proposta 
pedagógica que nos remete às atividades tradicionais, em que o objetivo é meramente informar, anunciar, apontar e demonstrar algo, estando, portanto, atrelado à memorização e não às metodologias que instigam o sujeito a refletir e criticar para construir conhecimentos. Entende-se a limitação e, até mesmo, o objetivo deste recurso, porém sua colocação pode ser feita de maneira estratégica no texto, trazendo não somente uma informação, mas uma indagação, uma possibilidade de reflexão sobre o assunto abordado (KRASILCHICK, 1987; SILVA; CICILLINI, 2010).

Pensando em metodologias com potencial de promoção do PC, observa-se que a categoria 2) Exploratórias contempla o maior número de descritores, os quais foram sistematizados em nove subcategorias, a saber: 2a. Estudo do texto; 2b. Exercícios; 2c. Desafios; 2d. Referências na Web; 2e. Atividades sobre o tema; 2f. Organização de ideias; $2 \mathrm{~g}$. Problematização; $2 \mathrm{~h}$. Interpretação de texto e 2i. Experimento. Nesta categoria ocorre o que se considera um arcabouço para a reflexão e para a criticidade. Embora as atividades não sejam totalmente intencionadas para a promoção ou desenvolvimento do PC, têm potencialidade de se aproximar desta função, levando o sujeito (aluno) a pesquisar, interpretar e pensar.

Assim ocorre na subcategoria $2 \mathrm{~d}$. Referências da Web, com os descritores Entrando na rede (10 em LDC 7; 4 em LDC 8), Conteúdo digital (7 em LDC 8; 10 em LDC 6) e Use a internet (18 em LDC 6), pois nessas atividades propõe-se uma pesquisa na internet ou no $C d$ que acompanha o LD, destaca-se que o CD como complemento dos LDCs foi uma exceção. O mesmo ocorre na subcategoria $2 \mathrm{~g}$. Problematização, com os descritores Motivação (27 em LDC 6), Ponto de partida/chegada (8 em LDC 5), A questão é (29 em LDC 5), Começando a unidade (7 em LDC 8; 8 em LDC 7), Porque estudar esta unidade (7 em LDC 8; 8 em LDC 7) e Seu aprendizado não termina aqui (19 em LDC 6), em que são propostas atividades que despertam a atenção do sujeito para a leitura e a investigação do conteúdo; geralmente encontram-se no início ou no final dos capítulos, desenvolvendo o papel de motivar o sujeito a aprender um novo conteúdo.

As atividades problematizadoras do conhecimento científico são consideradas cruciais para a promoção do PC, tornando-se semelhantes ao que se conhece como Atividades Baseadas em Problemas (ABP), que se configuram como "potencialmente facilitadoras do Pensamento Crítico, nomeadamente no desenvolvimento de capacidades relacionadas com a resolução de problemas" (FARTURA, 2007, p. 19). São, portanto, propulsoras da ação de pensar e agir de forma crítica sobre determinado assunto, encorajando os alunos a se comunicar, identificar informações relevantes, pesquisar, avaliar, refletir e criticar (ENNIS, 1985; TENREIRO-VIEIRA, 2000; TENREIRO-VIEIRA; VIEIRA, 2001; FARTURA, 2007; TAVARES, 2012).

Ainda na categoria 2) Exploratórias encontram-se atividades que se caracterizam por gerar um impacto positivo para a aprendizagem, como é o caso da subcategoria $2 \mathrm{i}$. Experimento, com os descritores: No laboratório (9 em LDC 4); Experimentação faça você mesmo (10 em LDC 1); Mãos à obra: atividade prática ou experimental (5 em LDC 2; 12 em LDC 3) e Aprendendo com a prática (10 em LDC 5). A forma como a atividade está disposta no LD, porém, não estimula o sujeito a pensar, resolver problemas, refletir, tampouco a criticar plenamente, isto porque os experimentos encontrados são extremamente simplistas, fazendo com que o sujeito apenas reproduza o que o LD apresenta, 
com expressões como: "Faça a mesma coisa" (LDC 1) e "Feche; Arrume; Coloque; Anote no caderno" (LDC 4). Essas expressões são autoritárias, conferindo ao enredo uma abordagem apontada como facilitadora da Ciência reproducionista, que, segundo Güllich e Silva (2013, p. 159), pode ser explicada pelo fato de "experiências [experimentos e práticas] somente serem exercidas pela cópia"; isso compromete a proposta pedagógica da atividade, pois torna os alunos meros receptores, passivos diante do processo de ensino e aprendizagem (GÜLLICH, 2004; WALCZAK; MATTOS; GÜLLICH, 2018).

$\mathrm{Na}$ subcategoria 2f. Organização de ideias consta o descritor destinado às atividades de Mapas Conceituais (19 em LDC 6), caracterizado por buscar sistematizar os principais conceitos para o estudo do conteúdo. Essa metodologia é muito utilizada e proporciona excelentes resultados para o desenvolvimento das capacidades do PC, pois auxilia nas tomadas de decisão, a pensar criticamente e a relacionar corretamente os conceitos (ENNIS, 1985; TENREIRO-VIEIRA, 2000; TENREIRO-VIEIRA; VIEIRA, 2001; FARTURA, 2007; TENREIRO-VIEIRA; VIEIRA, 2013b).

Esta atividade, todavia, já vem pronta no LD, o que se considera uma infeliz escoIha dos autores, tendo em vista que ocorre uma perda do potencial que essa estratégia possui para o pleno desenvolvimento do PC em Ciências. Considera-se que, pela falta de encaminhamento pedagógico do LD, esta atividade perde o seu potencial, pois, se a proposta fosse a de construir um mapa conceitual, o aluno teria a oportunidade de explorar a sua criatividade por meio de suas ideias e compreensões, demonstrando o seu senso crítico e reflexivo. Assim, a atividade teria valor educativo ampliado, auxiliando no desenvolvimento intelectual do aluno e na construção do seu próprio mapa conceitual, de acordo com o que julgasse relevante.

As estratégias mais adequadas de ensino, em termos de competência para promoção/desenvolvimento do PC em Ciências, encontradas nos LDCEFs analisados, foram as sistematizadas na categoria 3) Reflexivas/Críticas, na qual estão elencados todos os descritores com maior potencial educativo, distribuídos nas subcategorias: 3a. Trabalho em Grupo; 3b. Pesquisa; 3c. Prática pedagógica; 3d. Abordagem CTS/CTSA e 3e. Oficinas. Acredita-se que as atividades elencadas nessas subcategorias são plenamente adequadas para a promoção do PC em Ciências, mas cabe destacar a subcategoria 3d. Abordagem CTSA, que conta com os descritores: Ciência (12 em LDC 4); Por uma nova atitude (8 em LDC 7; 8 em LDC 8); Ciência Tecnologia, Sociedade e Ambiente em Pauta (15 em LDC 7; 5 em LDC 8) e Boxes CTS (33 em LDC 5). A inserção de atividades que abordam as correlações entre Ciência, Tecnologia, Sociedade e Ambiente (CTSA) é de suma importância para o ensino e para o desenvolvimento das capacidades do PC em ciências pois, como afirma Freire (2007, p. 14), o enfoque CTSA

[...] requer muito mais do que trabalhar com temas e assuntos científicos e tecnológicos socialmente relevantes. Requer, igualmente, desenvolver o pensamento crítico com os alunos, de modo a auxiliá-los a desmitificar muitas situações que envolvem Ciência e Tecnologia, observar os fatos cotidianos sob diferentes pontos de vista, sem render-se ingenuamente às modas pré-fabricadas de pensamento, aos jargões e chavões de opinião coletiva, aos modismos e ao consumo sem reflexão e crítica. 
Considera-se, portanto, a abordagem CTSA como uma possibilidade de desenvolvimento das habilidades relativas ao PC; por exemplo: o senso crítico, tomadas de decisão, autonomia, formulação de hipóteses, entre outras capacidades que possuem potencial de desenvolver a autonomia do sujeito (FREIRE, 2007).

Na discussão sobre as estratégias indispensáveis para um ensino de Ciências contextual, investigativo e crítico, aponta-se para a discussão da subcategoria 3b. Pesquisa, que possui os seguintes descritores: Pensando e pesquisando (20 em LDC 1); Tema para pesquisa (10 em LDC 6); Mexa-se (15 em LDC 5) e Isso vai para o nosso mural (4 em LDC 6). Sem dúvidas, a ação de pesquisar é essencial para a aprendizagem, pois somente por meio da investigação o sujeito é capaz de ampliar os seus conhecimentos e construir novos. Em contrapartida, o sujeito "[...] que não pesquisa ou que simplesmente não investiga os fatos está fadado a tornar-se um mero reprodutor de conhecimentos, sem o entendimento dos fenômenos e situações" (FREIRE, 2007, p. 21). Por conta disso, a atividade de pesquisa precisa ser planejada, articulada, fundamentada e mediada; nesse sentido, Ninin (2008, p. 19) adverte que

a atividade de pesquisa [...] nem sempre cumpre seu papel em relação ao desenvolvimento do pensamento crítico dos alunos e à construção de conhecimentos. Mostra-se muito mais como uma atividade em que os estudantes revelam sua dependência e sua falta de autonomia em relação à discussão de determinado assunto, visto que se resume a um texto composto de fragmentos de outros textos e/ou de informações obtidas por meio de buscas na internet, quase sempre copiadas e pouco argumentadas pelos estudantes-autores.

O autor supracitado complementa, ainda, afirmando que cópias ou simples buscas na internet, sem a mediação do educador, "não podem ser consideradas como desencadeadoras do pensamento crítico dos alunos, uma vez que pouco ou nada exploram seus pontos de vista e, menos ainda, propiciam ambientes para que a argumentação seja exercitada" (2008, p. 19). Dessa forma, vem à tona, novamente, a necessidade de o professor de ciências possuir uma formação que priorize a pesquisa como estratégia de ensino, pois o "educar pela pesquisa possibilita [...] a construção da competência profissional com autonomia" (GALIAZZI; MORAES, 2002, p. 248), tornando o professor autônomo o suficiente para assumir o papel de pesquisador crítico, reflexivo e investigativo, inserindo e mediando a atividade de pesquisa em sua prática docente, ou seja, capaz de desenvolver um/a ensino/aula com pesquisa.

Assim, compreende-se que "o envolvimento constante em pesquisa ajuda na construção de competências docentes, capazes de propiciar as condições de intervenção crítica e criativa na realidade" (GALIAZZI; MORAES, 2002, p. 249). Ainda segundo Galiazzi e Moraes (2002, p. 248), por meio do educar pela pesquisa "[...] emergem aprendizagens privilegiadas, o conhecer se (re)significa como oportunidade de desenvolvimento, desenvolvimento humano com autonomia e qualidade", voltada para a formação/constituição/produção das competências de PC nos sujeitos.

Cabe, ressaltar, ainda, que as demais subcategorias reflexivas/críticas também exercem papel fundamental para o ensino de Ciências se bem planejadas e mediadas. Defende-se que as atividades encontradas na subcategoria 3a. Trabalho em Grupo, 3c. Prática pedagógica e 3e. Oficinas, também possuem um grande potencial para o desen- 
volvimento das capacidades do PC. Ao contrário das demais, na categoria 3) Reflexivas/ Críticas as atividades estimulam o aluno com expressões de incentivo, instigando-o a: "Interpretar; Discutir em grupo; Refletir; Tomar uma decisão" (LDC8, 2010); "Explorar o tema; Compartilhar; Obter informações; Trocar ideias" (LDC7, 2014), propondo ações muito importantes para a promoção do PC, além de contribuir para o crescimento pessoal, social e intelectual dos sujeitos envolvidos.

Diante do exposto, concorda-se com o que afirma Fagundes (2007, p. 320), quando assevera que: "[...] a escola pode envolver o aluno de tal maneira que ele deixe de ser ouvinte e repetidor de informações fornecidas pelo professor ou pelo livro, para se tornar sujeito de sua aprendizagem, refletindo conscientemente sobre os temas estudados[...]". Dessa forma, reforça-se o argumento de que um ponto-chave está na capacidade de os educandos desenvolverem suas ações em torno do PC e, sobretudo, na influência das metodologias de ensino escolhidas e mediadas para tornar a escola um espaço crítico e reflexivo. Assim, o LD pode facilitar o processo de aprendizagem, porém o professor mediador, e com formação adequada, é que definirá os caminhos e itinerários formativos com seus alunos para produzir uma boa aula de ciências.

\section{CONCLUSÃO}

A partir da análise temática realizada nos oito LDCEFs emergiram três categorias, as quais representam as subcategorias e seus descritores de acordo com a potencial de promoção do PC. Com isso, observa-se que as atividades da categoria 1) Informativas tiveram menor incidência nos LDCs, o que se entende como algo positivo, considerando que atividades desse cunho não representam metodologias atrativas, posto que apresentam traços marcantes das atividades tradicionais, as quais estão atreladas à memorização e reprodução, o que, eventualmente, pode tornar-se um entrave para a introdução do PC no processo de ensino e aprendizagem das ciências.

Em contrapartida, pode-se também observar, com base na análise dos dados, que as atividades sistematizadas na categoria 2) Exploratórias foram as mais abundantes nos enredos dos LDCs, o que se considera um resultado satisfatório do ponto de vista de que essas atividades, se bem mediadas, possuem potencial para gerar reflexão, investigação, autonomia e, assim, a produção de conhecimentos significativos, dentre outras ações e comportamentos colaborativos no processo de construção de conhecimentos, podendo desenvolver, desse modo, as esperadas capacidades do PC. Dado o exposto, acredita-se que uma das possibilidades seja o investimento na formação de professores em uma perspectiva crítica e reflexiva, a qual pode refletir em uma melhoria no cenário educacional, uma vez que o uso que o professor dará/fará ao/do LD, em boa medida, poderá refletir nos (des)caminhos da formação de seus alunos.

As atividades que representam a essência da promoção do PC foram sistematizadas na categoria 3) Reflexivas/Críticas e ocorreram em menor número, comparada com a ocorrência da segunda categoria, que descreve as atividades exploratórias. Entende-se a potencialidade das estratégias didáticas que têm, em sua essência, um caráter instigador, reflexivo e autônomo, que permite ao sujeito (re)criar suas próprias ideias, valorizando o seu senso crítico e reflexivo. Desta forma, acredita-se que as metodologias classificadas neste estudo como Reflexivas/Críticas são as mais indicadas para a promo- 
ção do PC, capazes de desenvolver capacidades pertinentes ao sujeito, ampliando a sua concepção sobre o meio em que está inserido, instigado o mesmo a compreender a sua capacidade de atuar e transformar o cenário em que vive. Evidentemente, portanto, que se busca uma maior representatividade dessas atividades nos LDCs, porém, como mencionado, as atividades exploratórias podem ser desenvolvidas em um viés tão crítico quanto as elencadas na terceira categoria.

Para que os melhores encaminhamentos sejam dados com o material didático disponível, aponta-se para a necessidade de um olhar crítico sob as diretrizes educacionais (políticas públicas) que orientam a formação de professores, além das melhorias nos próprios LDCs, nos quais as pesquisas brasileiras, com suas análises e críticas, desempenham papel fundamental. Entende-se a necessária aproximação das relações dos principais envolvidos direta ou indiretamente no processo de ensino e aprendizagem. A inserção do PC nestes contextos permite o desenvolvimento de maiores discussões e avanços dessa temática, com o enfoque de analisar e desenvolver estratégias/metodologias de ensino que possam ser revertidas a médio e longo prazos em tomadas de decisão responsivas.

\section{REFERÊNCIAS}

AMARAL, Ivan Amorosino do. Os fundamentos do ensino de ciências e o livro didático. In: FRACALANZA, Hilário; MEGID NETO, Jorge (org.). O livro didático de ciências no Brasil. Campinas: Komedi, 2006.

BRASIL. Congresso. Senado. Lei no 9.394, de 20 de dezembro de 1996. Lei de Diretrizes e Bases da Educação Nacional. 3. ed. Brasília, DF, 2005. p. 1-64. Disponível em: https://www2.senado.leg.br/bdsf/bitstream/handle/id/70320/65.pdf. Acesso em: 22 nov. 2018.

BRASIL. Ministério da Educação. Orientações curriculares para Ensino Médio: ciências humanas e suas tecnologias. Brasília, DF, 2006. Disponível em: http://portal.mec.gov.br/seb/arquivos/pdf/book_volume_03_internet.pdf. Acesso em: 10 maio 2017.

DEWEY, John. Como pensamos. Barcelona: Paidós, 1989.

ENNIS, Robert. A logical basis for measuring critical thinking skills. Educational Leadership, Alexandria: ASCD, v. 43, n. 2, 1985.

ENNIS, Robert. Critical thinking and the curriculum. National Forum, v. 65, n. 1, p. 24-27, 1985.

FAGUNDES, Suzana Margarete Kurzmann. Experimentação nas aulas de ciências: um meio para a formação da autonomia? In: GALIAZZI, Maria do Carmo et al. Construção curricular em rede na educação em ciências: uma aposta de pesquisa na sala de aula. ljuí: Ed. Unijuí, 2007. p. 317-336.

FARTURA, Susana Gomes. Aprendizagem baseada em problemas orientada para o pensamento crítico: um estudo no âmbito da Educação em Ciências no 1ㅇ Ciclo do Ensino Básico. 2007. 333 f. Dissertação (Mestrado) - Curso de Departamento de Didáctica e Tecnologia Educativa, Universidade de Aveiro, Aveiro, 2007. Disponível em: https://ria.ua.pt/bitstream/10773/1289/1/2007001195.pdf. Acesso em: 3 jan. 2018.

FRACALANZA, Hilário. Livro didático de ciências: novas ou velhas perspectivas. In: FRACALANZA, Hilário; MEGID NETO, Jorge (org.). O livro didático de ciências no Brasil. Campinas: Komedi, 2006b. p. 174-195.

FRACALANZA, Hilário; MEGID NETO, Jorge. O livro didático de ciências: problemas e soluções. Ciências \& Educação, São Paulo, v. 9, n. 2, p. 147-157, 2003. Disponível em: http://www.scielo.br/pdf/ciedu/ v9n2/01.pdf. Acesso em: 7 jan. 2019.

FRACALANZA, Hilário. O ensino de ciências no Brasil. In: FRACALANZA, Hilário; MEGID NETO, Jorge (org.). O livro didático de ciências no Brasil. Campinas: Komedi, 2006a. p. 127-149.

FREIRE, Leila Inês Follmann. Pensamento crítico, enfoque educacional CTS e o ensino de química. 2007. 175 f. Dissertação (Mestrado) - Universidade Federal de Santa Catarina, Curso de Educação Científica e Tecnológica, Programa de Pós-Graduação em Educação Científica e Tecnológica, Florianópolis, 2007. Disponível em: https://repositorio.ufsc.br/bitstream/handle/123456789/89901/245569.pdf?sequence. Acesso em: 1ㅇ fev. 2018. 
GALIAZZI, Maria do Carmo; MORAES, Roque. Educação pela pesquisa como modo, tempo e espaço de qualificação da formação de professores de ciência. Ciência \& Educação, Bauru, v. 8, n. 2, p. 237-252, nov. 2002. Disponível em: http://www.scielo.br/pdf/ciedu/v8n2/08.pdf. Acesso em: 10 abr. 2018.

GERALDI, Corinta Maria Grisolia. Currículo em ação: buscando a compreensão do cotidiano da escola básica. Pro-posições, Belo Horizonte, v. 5, n. 3, p. 111-132, nov.1994. Disponível em: https://www.fe.unicamp.br/pf-fe/publicacao/1827/15_artigo_geraldicmg.pdf. Acesso em: 20 out. 2016.

GÜLLICH, Roque Ismael da Costa. Desconstruindo a imagem do livro didático no ensino de ciências. Revista Setrem, Três de Maio, v. 4, n. 3, p. 43-51, jan. 2004.

GÜLLICH, Roque Ismael da Costa. Investigação-formação-ação em ciências: um caminho para reconstruir a relação entre livro didático, o professor e o ensino. Curitiba: Prismas, 2013.

GÜLLICH, Roque Ismael da Costa; SILVA, Lenice Heloísa de Arruda. O enredo da experimentação no livro didático: construção de conhecimentos ou reprodução de teorias e verdades científicas? Ensaio Pesquisa em Educação em Ciências, Belo Horizonte, v. 15, n. 2, p. 155-167, 2013.

GÜLLICH, Roque Ismael da Costa; SILVA, Lenice Heloísa de Arruda.; ANTUNES, Fabiano. Os professores que ensinam ciências e o livro didático: reflexões coletivas no contexto de um grupo de estudos. Ensino de Ciências e Tecnologia em Revista, Santo Ângelo, v. 1, n. 2, p. 76-86, jul./dez. 2011.

GÜLLICH, Roque Ismael da Costa; WALCZAK, Aline Teresinha; MATTOS, Kélli Renata Corrêa de. Experimentação investigativa nos livros didáticos de biologia. SBEnBIO, Maringá, n. 9, p. 392-403, 2016. Disponível em: http://sbenbio.org.br/wp-content/uploads/edicoes/revista_sbenbio_n9.pdf. Acesso em: 24 nov. 2017.

KRASILCHIK, Myriam. O professor e o currículo das ciências. São Paulo: EPU, 1987.

LÜDKE, Menga; ANDRÉ, Marli Elisa Dalmazo Afonso de. Pesquisa em educação: abordagens qualitativas. São Paulo: EPU, 2001.

MARIM, Vlademir; SOUZA, Anália Barreto. Os livros didáticos de matemática: concepção do professor do ensino médio nas escolas públicas. Revista de Educação, Ciências e Matemática, Rio de Janeiro, v. 5, n. 2, p. 111-124, maio 2015. Disponível em: http://publicacoes.unigranrio.edu.br/index.php/recm/article/ view/2801/1439. Acesso em: 17 abr. 2018.

MATTOS, Kélli Renata Corrêa de et al. Pensamento crítico em ciências: análise das produções. In: CONGRESSO INTERNACIONAL DE EDUCAÇÃO CIENTÍFICA E TECNOLÓGICA, 4., 2017. Santo Ângelo. Anais [...]. Santo Ângelo, 2017.

NININ, Maria Otilia Guimarães. Pesquisa na escola: Que espaço é esse? O do conteúdo ou o do pensamento crítico? Educação em Revista, Belo Horizonte, v. 2, n. 48, p. 17-35, dez. 2008. Disponível em: http://www.scielo.br/pdf/edur/n48/a02n48.pdf. Acesso em: 3 jan. 2018.

NÚÑEZ, Isauro Beltrán et al. A seleção dos livros didáticos: um saber necessário ao professor. O caso do ensino de ciências. Revista Iberoamericana de Educación, Madrid, v. 33, n. 1 (Número especial), 2003.

OSSAK, Ana Lídia; BELLINI, Marta. O livro didático em ciências: condutor docente ou recurso pedagógico? Ensino, Saúde e Ambiente, Maringá: UEL, v. 2, n. 3, p. 2-22, dez. 2009.

ROSA, Marcelo D’Aquino; MOHR, Adriana. Seleção e uso do livro didático: um estudo com professores de Ciências na rede de ensino municipal de Florianópolis. Ensaio Pesquisa em Educação em Ciências, v. 18, n. 3, p. 97-115, dez. 2016. FapUnifesp (SciELO). http://dx.doi.org/10.1590/1983-21172016180305. Disponível em: http://www.scielo.br/pdf/epec/v18n3/1983-2117-epec-18-03-00097.pdf. Acesso em: 5 jan. 2018. SELLES, Sandra Escovedo; FERREIRA, Marcia Serra. Influências histórico-culturais nas representações sobre as estações do ano em livros didáticos de ciências. Ciência \& Educação, Bauru, v. 10, n. 1, 2004.

SILVA, Elenita Pinheiro de Queiroz; CICILLINI, Graça Aparecida. Tessituras sobre o currículo de ciências: histórias, metodologias e atividades de ensino. In: SEMINÁRIO NACIONAL: CURRÍCULO EM MOVIMENTO - PERSPECTIVAS ATUAIS, 1., 2010, Belo Horizonte. Anais [...]. Belo Horizonte, 2010.

SILVA, Patricia Vieira da. De "Um Para Todos" a "Todos Para Todos": as mudanças socioculturais da cultura de massas à cultura digital. In: VILAÇA, Márcio Luiz Corrêa; ARAUJO, Elaine Vasquez Ferreira de (org.). Tecnologia, sociedade e educação na era digital. Duque de Caxias: Unigranrio, 2016. p. 41-70. Cap. 2. Disponível em: http://www.pgcl.uenf.br/arquivos/tecnologia,sociedadeeeducacaonaeradigital_011120181554. pdf. Acesso em: 16 jun. 2020.

TAVARES, Bruno Filipe Correia. A escultura como promotora do pensamento crítico. 2012. $104 \mathrm{f}$. Dissertação (Mestrado em Mestre em Ensino das Artes Visuais) - Universidade de Aveiro, Departamento de Educação, Portugal, 2012. 
TENREIRO-VIEIRA, Celina. Formação em pensamento crítico de professores de ciências: impacte nas práticas de sala de aula e no nível de pensamento crítico dos alunos. Revista Electrónica de Enseñanza de las Ciencias, Aveiro, v. 3, n. 3, p. 228-256, dez. 2004. Disponível em: http://reec.uvigo.es/volumenes/volumen3/REEC_3_3_1.PDF. Acesso em: 3 jan. 2018.

TENREIRO-VIEIRA, Celina. O pensamento crítico na educação científica. Lisboa: Instituto Piaget, 2000.

TENREIRO-VIEIRA, Celina; VIEIRA, Rui Marques. Construindo práticas didático-pedagógicas promotoras da literacia científica e do pensamento crítico. 2. ed. Madrid: OEI - Organização dos Estados Ibero-americanos; Iberciencia, 2014. 72 p. Disponível em: http://www.ibercienciaoei.org/doc2.pdf. Acesso em: 1으 fev. 2018.

TENREIRO-VIEIRA, Celina; VIEIRA, Rui Marques. Estratégias de ensino/aprendizagem: o questionamento promotor do pensamento crítico. Lisboa: Instituto Piaget, 2001.

TENREIRO-VIEIRA, Celina; VIEIRA, Rui Marques. Estratégias de ensino e aprendizagem e a promoção de capacidades de pensamento crítico. In: CONGRESO INTERNACIONAL SOBRE INVESTIGACIÓN EN DIDÁCTICA DE LAS CIENCIAS, 9., Universidade de Girona. Anais [...]. Girona, 2013a.

TENREIRO-VIEIRA, Celina; VIEIRA, Rui Marques. Literacia e pensamento crítico: um referencial para a educação em ciências e em matemática. Revista Brasileira de Educação, Rio Janeiro, v. 18, n. 52, p. 162-242, jan./mar. 2013b.

WALCZAK, Aline Teresinha.; MATTOS, Kélli Renata Corrêa de; GÜLLICH, Roque Ismael da Costa. O que dizem os livros didáticos de Biologia sobre a experimentação?! Ensino\&Pesquisa, União da Vitória, v. 15, n. 3, p. 221-237, set./dez. 2017. Disponível em: http://periodicos.unespar.edu.br/index.php/ensinoepesquisa/article/view/994/pdf_31. Acesso em: 24 nov. 2017.

WALCZAK, Aline Teresinha; MATTOS, Kélli Renata Corrêa de; GÜLLICH, Roque Ismael da Costa. A ciência reproducionista nos livros didáticos de biologia: um monólogo sobre a experimentação. Revista Areté Revista Amazônica de Ensino de Ciências, v. 11, n. 23, p. 1-10, mar. 2018. ISSN 1984-7505. Disponível em: http://periodicos.uea.edu.br/index.php/arete/article/view/860. Acesso em: 25 mar. 2018.

\section{Referências dos livros analisados}

BARROS, Carlos; PAULINO, Wilson. Ciências: os seres vivos. 4. ed. São Paulo: Ática, 2009. 256 p.

BARROS, Carlos; PAULINO, Wilson. Ciências: o corpo humano. São Paulo: Ática, 2006. 248 p.

CANTO, Eduardo Leite. Ciências naturais: aprendendo com o cotidiano. 4. ed. São Paulo: Moderna, 2012. $272 \mathrm{p}$.

CARNEVALLE, Maíra Rosa (org.). Projeto Araribá: ciências. 4. ed. São Paulo: Moderna, 2014. 248 p.

CÉSAR, Silva Júnior; SEZAR, Sasson; BEDAQUE, Paulo Sérgio Sanches. Entendendo a natureza: o homem no ambiente. São Paulo: Saraiva, 2001. 208 p.

GEWANDSZNAJDER, Fernando. Ciências: a vida na terra. São Paulo: Ática, 2012. 352 p.

SHIMABUKURO, Vanessa (org.). Projeto Araribá: ciências. 3. ed. São Paulo: Moderna, 2010. 232 p.

TRIVELLATO, José et al. Ciências. São Paulo: Quinteto, 2015. 400 p. 